\title{
Anodic Aluminum Oxide Templated Channel Electrodes via Atomic Layer Deposition
}

\author{
A. B. F. Martinson ${ }^{\mathrm{a}, \mathrm{b}}$, J. W. Elam ${ }^{\mathrm{b}}$, J. T. Hupp ${ }^{*}, \mathrm{a}$, M. J. Pellin ${ }^{\mathrm{b}}$ \\ ${ }^{a}$ Department of Chemistry, Northwestern University, Evanston, Illinois 60208, USA \\ ${ }^{b}$ Argonne National Lab, Division of Materials Science, Argonne, Illinois 60439, USA
}

Dye-sensitized solar cells (DSSCs) utilize high surface area metal oxide sintered particle networks to absorb molecular dyes and transport injected charge carriers. While this sintered particle architecture allows liquid electrolyte DSSCs to achieve efficiencies up to $11 \%$, slow charge transport through the semiconductor network limits the amount of modification that can be made to the electrolyte and dye without adversely affecting the efficiency. The functionalization of anodic aluminum oxide membranes with thin films of transparent, semiconducting oxides via atomic layer deposition may allow for significantly faster charge transport. We demonstrate the fabrication of $\mathrm{ZnO}$ thin films within and upon commercially available anodic aluminum oxide membranes via atomic layer deposition.

\section{Introduction}

Dye sensitized solar cells (DSSCs) comprise an increasingly attractive alternative energy conversion technology. $(1,2)$ These photoelectrochemical cells use molecular dyes to sensitize high area, wide band gap semiconductor oxide photoanodes. Typically, a liquid electrolyte based on iodide/triiodide scavenges the hole left on the dye and shuttles it to a Pt-coated counter electrode where the circuit is completed. Solid-state (molecular or polymeric) hole scavenger/conductor have also been used.(2) The most efficient DSSCs convert AM1.5 solar insolation to electrical energy with $11 \%$ efficiency, but suffer from relatively poor photovoltages due to the overpotential needed to drive the dye regeneration reaction. Furthermore, they show less than optimal photocurrents due to insufficient light collection at wavelengths $>700 \mathrm{~nm} .(3)$

Compared to the most efficient nanocrystalline $\mathrm{TiO}_{2}$ photoanodes, devices fabricated with $\mathrm{ZnO}$ electrodes show significantly lower conversion efficiencies (4\%).(4-6) Despite superior recombination dynamics, poor dye loading and charge injection into $\mathrm{ZnO}$ reduce the total photocurrent yield.(7) Yet ZnO DSSCs continue to be actively investigated due to the ease with which alternative and potentially superior high-area semiconductor morphologies may be fabricated. Particularly interesting are nominally 1-D arrays. Compared with standard photoanodes based on sintered nanocrystalline particles, 1-D photoanodes should show significantly faster electron transport, owing to a more direct path to the conductive glass electrode combined with fewer sites for trapping electrons. To this end, several novel photoanode architectures have been fabricated, including but not limited to hydrothermally grown $\mathrm{ZnO}$ nanorod arrays, electrodeposited $\mathrm{ZnO}$ platelets, and $\mathrm{TiO}_{2}$ pores formed via titanium anodization.(8-10) In the most successful application of this idea to date, a $1.5 \%$ efficient $\mathrm{ZnO}$ nanorod array has been shown to exhibit significantly faster transport compared to nanoparticle networks.(11, 12) The efficiency 
of the nanorod devices, however, is limited by the low surface area of the framework. Increasing the surface area of the nanorod array depends on growing higher aspect ratio rods via hydrothermal methods, which remains a significant challenge.(13)

Here we report a novel 1-D photoanode design with the potential for surface areas comparable to nanocrystalline sintered particle networks. Using anodic aluminum oxide (AAO) membranes as an inert and transparent template, atomic layer deposition (ALD) is utilized to grow thin films of transparent, semiconducting oxides on the pore wall. The result is a metal oxide general route to arrays of nanotubes suitable for use in DSSCs.

\section{Experimental}

For the $\mathrm{ZnO}$-based cells, a $64 \mu \mathrm{m}$ thick membrane with $210 \mathrm{~nm}$ pores that is $25-50 \%$ porous (Anodisc, Whatman) was coated with $\mathrm{ZnO}$ by $\mathrm{ALD}$ via alternate exposure to diethyl zinc and water at $200^{\circ} \mathrm{C}$. The membranes were then fired at $400^{\circ} \mathrm{C}$ in air for 30 minutes. A $1 \mu \mathrm{m}$ thick electrode composed of transparent, conductive aluminum-doped zinc oxide (AZO) was deposited on one side of the membrane side ALD. The commercial AAO membranes employed in this study have pores that narrow to $20 \mathrm{~nm}$ within the last micron of thickness of one side. During deposition of the thick electrode, a steel fixture masked all but the small-pore face of the membrane. To improve the electrical contact to the AZO coating, Au was evaporated onto the coating along the edges of the AAO membrane.

After heating to $200^{\circ} \mathrm{C}$ and subsequent cooling to $80^{\circ} \mathrm{C}$ the warm membranes were soaked in $0.5 \mathrm{mM}\left(\mathrm{Bu}_{4} \mathrm{~N}\right)_{2}\left[\mathrm{Ru}(4,4 \text { '-(COOH)-2,2'-bipyridine })_{2}(\mathrm{NCS})_{2}\right]$ ("N719", Dyesol, B2 dye) in ethanol for 30 min followed by a quick rinse with acetonitrile. A $50 \mu \mathrm{m}$ thick Surlyn frame separated the open-pore side of the membrane and a platinized fluorinedoped tin oxide (FTO) electrode. Light pressure was applied at $130^{\circ} \mathrm{C}$ to seal the cell. A solution of $0.5 \mathrm{M} \mathrm{LiI}, 0.05 \mathrm{mM} \mathrm{I}_{2}$, and $0.5 \mathrm{M} t$-butylpyridine in 3-methoxypropionitrile was introduced into the cell via vacuum backfilling through a hole in the FTO electrode. Additional Surlyn and a microscope cover slip sealed the electrolyte into the cell. Active areas were limited to $0.28 \mathrm{~cm}^{2}$. AM1.5 efficiencies were measured on a Class A solar cell analyzer from Spectra-Nova Technologies.

\section{Results and Discussion}

As expected for an ALD sequence entailing sufficient exposure times, the resulting polycrystalline $\mathrm{ZnO}$ film is continuous and conformal, Figure 1. Measurements of the resistance through the $64 \mu \mathrm{m}$ thickness of the membrane ( 48 $\Omega, 8 \mathrm{~nm}$ thick $\mathrm{ZnO})$ provide additional evidence that coatings span the length of the pores. As-deposited, ALD $\mathrm{ZnO}$ has numerous oxygen vacancies that make films moderately conductive and account for the relatively low resistance. A ZnO grain size of $\sim 20 \mathrm{~nm}$ may be directly observed by SEM and is corroborated by X-ray diffraction data. 


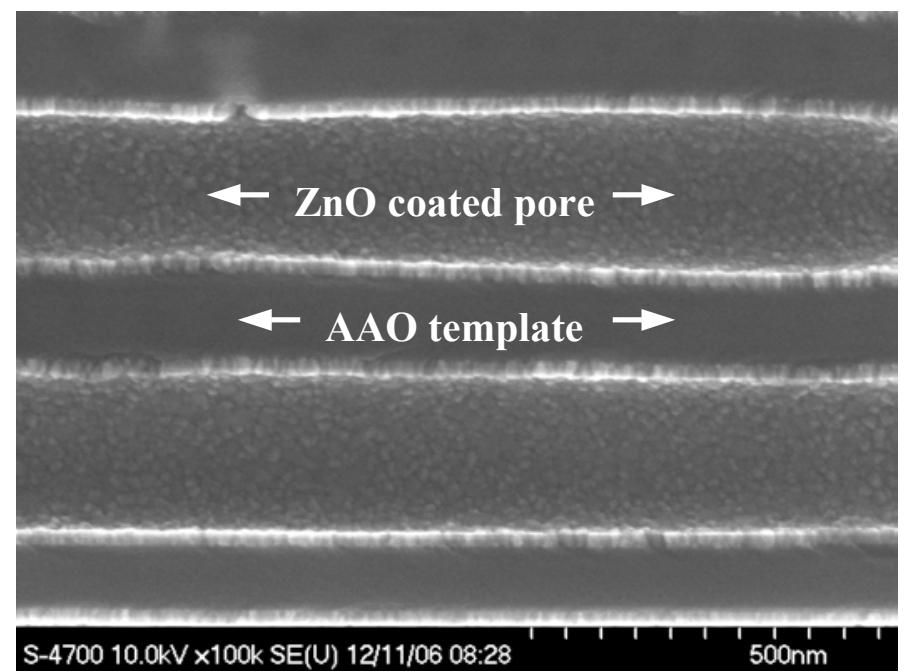

Figure 1. Commercial AAO template conformally coated with $20 \mathrm{~nm}$ of $\mathrm{ZnO}$ by ALD. Adapted from ref (14).

As shown in Figure 2, a thick coating of AZO was applied selectively to one side of the membrane by ALD. The combination of narrow pore termini and short exposure times $(0.15 \mathrm{~s})$ prevented the typically conformal deposition technique from significantly coating the pore interiors.

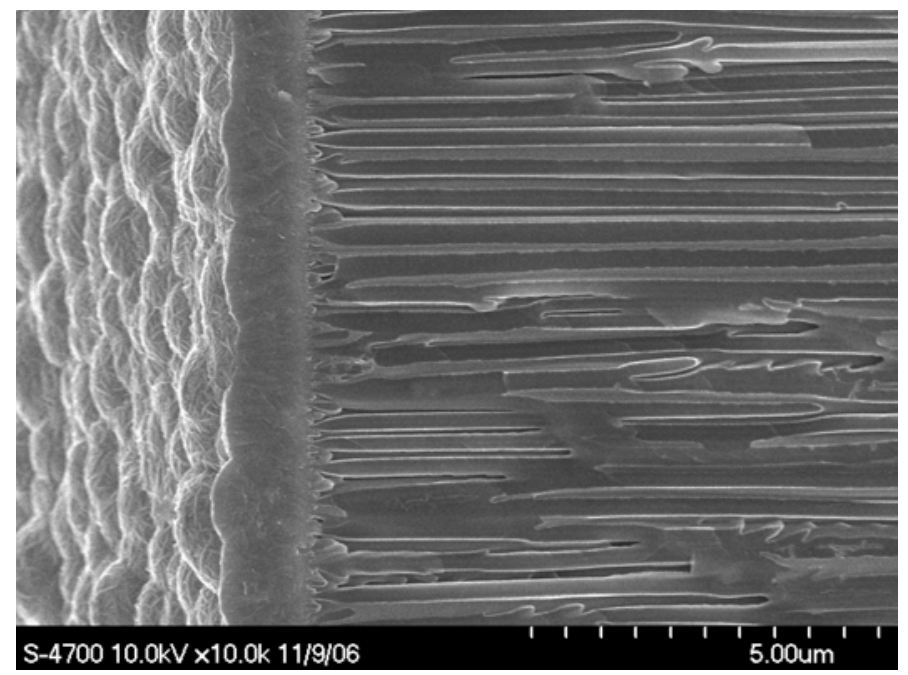

Figure 2. Commercial AAO template with thick AZO electrode deposited by ALD.

A large literature exists describing the theory and methodology for fabricating freestanding AAO membranes with hexagonally ordered pores ranging in size from 10$300 \mathrm{~nm}$ and pore densities in excess of 100 billion pores $/ \mathrm{cm}^{2} .(15-17)$ For this study, commercial membranes with modest surface area were selected for their ready availability. The roughness factor of the commercial disc may be estimated from the geometry of hexagonally ordered pores: 


$$
R F=\frac{4 \pi}{\sqrt{3}} \frac{r t}{s^{2}}
$$

where $r, t$ and $s$ are the pore radius, membrane thickness, and center-to-center pore spacing, respectively. Although poorly ordered, an average spacing of $329 \mathrm{~nm}$ suggests an RF on the order of 450 . The measured nitrogen isotherm on 50 discs yield a BET surface area of $9.02 \mathrm{~m}^{2} / \mathrm{g}$ (Figure 3 ). The resulting roughness factor of approximately 485 agrees with the above calculations.

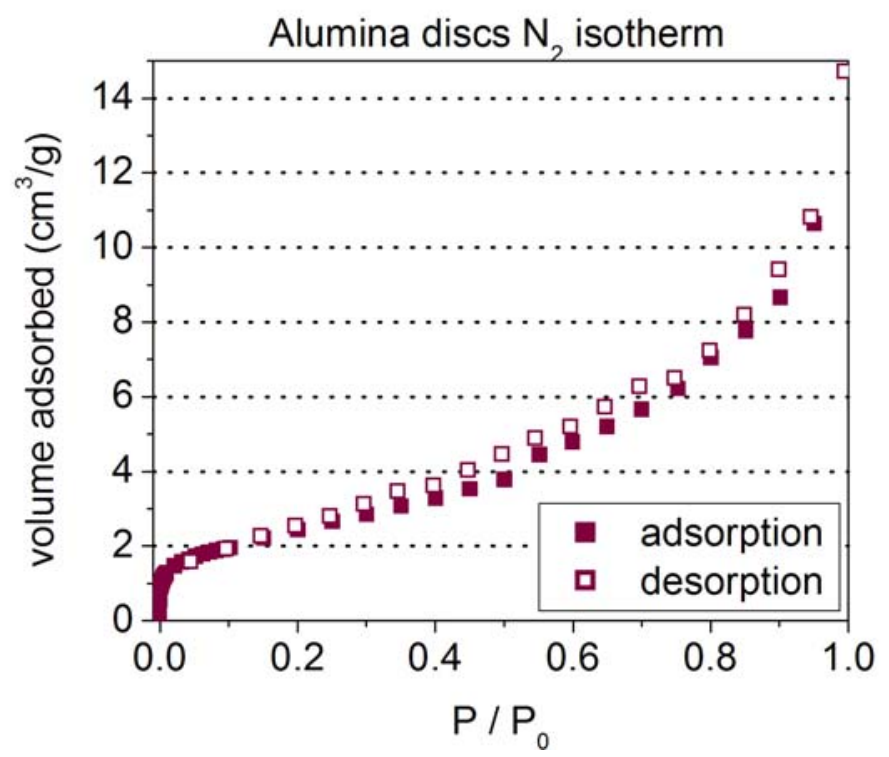

Figure 3. Nitrogen uptake of 50 commerical AAO membranes.

Figure 4 shows the AM1.5 power efficiency $\left(\eta_{p}\right)$ for a series of devices with increasing nanotube wall thickness. In the control device, lacking $\mathrm{ZnO}, \eta_{\mathrm{p}}$ is extremely low. This is not surprising given that the useful surface area is similar to that of a flat electrode. The facile parasitic reaction of the redox shuttle with the thick TCO electrode at the end of each pore may also limit performance. With the thinnest tube walls relatively small amounts of charge are collected by the AZO electrode, most likely due to a combination of slow charge transport through the $\mathrm{ZnO}$ and accelerated recombination owing to high steady-state concentrations of injected electrons. As the nanotube walls thicken, electrons flow more freely and $\eta_{\mathrm{p}}$ increases to a peak of value of $1.6 \%$. Subsequent tapering with thicker walls is consistent with decreasing surface area, and therefore light harvesting efficiency, due to a smaller pore radius. (Figure 5). 


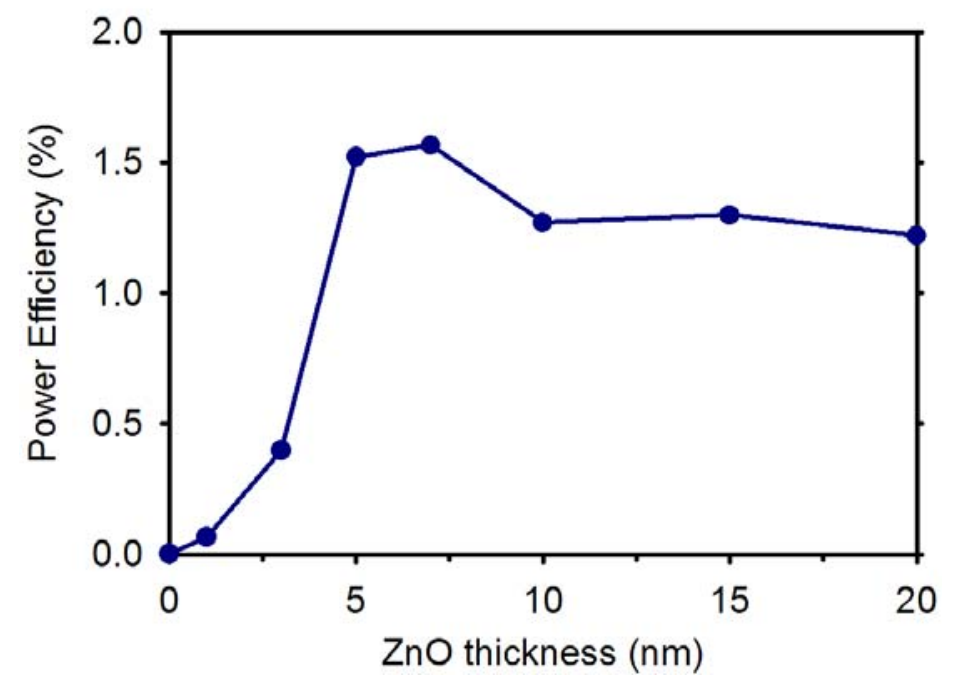

Figure 4. Power conversion efficiency under AM1.5 illumination as a function of $\mathrm{ZnO}$ nanotube wall thickness.

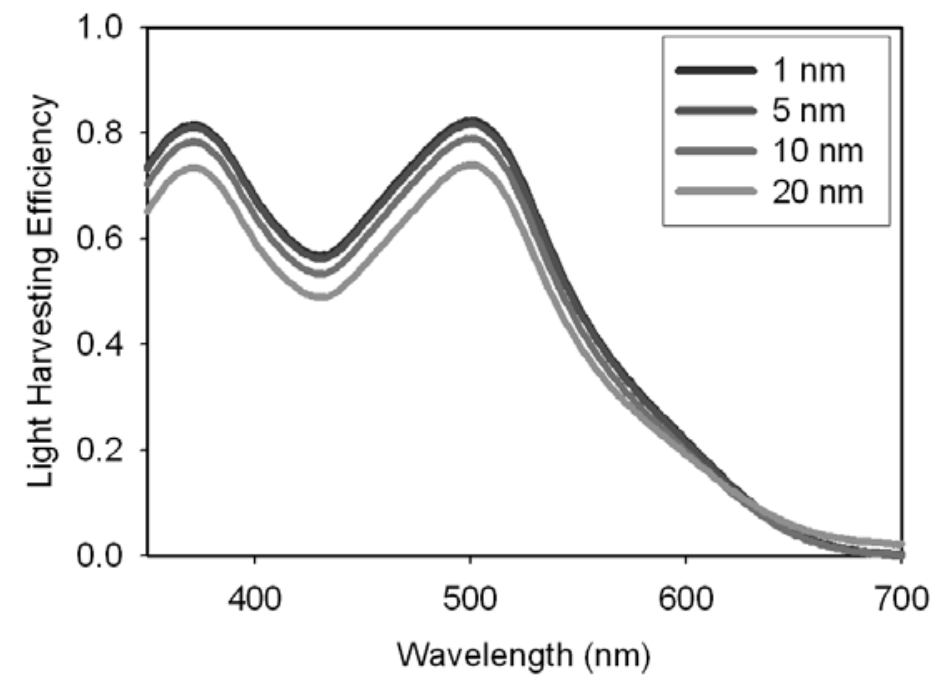

Figure 5. Light harvesting efficiency of dye desorbed from photoanodes with increasing $\mathrm{ZnO}$ pore wall thickness.

\section{Conclusion}

$\mathrm{ZnO}$ channel electrodes have been incorporated into dye-sensitized solar cells where they display reasonable light harvesting efficiency and moderate power efficiency. While the novel devices compare favorably with other ZnO-based DSSCs, an increased surface area will clearly be needed in order to obtain overall energy conversion efficiencies approaching that of the best $\mathrm{ZnO}$ cells. Current research is focused on determining the extent to which custom-made membranes and other semiconductors may improve photoanode performance. 


\section{Acknowledgments}

The work at Northwestern is supported by the U.S. Department of Energy, Basic Energy Sciences Program, under Grant DE-FG02-87ER13808 and by BP Solar. Work at Argonne is supported by the U.S. Department of Energy, BES-Materials Sciences under Contract W-31-109-ENG-38. Electron microscopy was performed at the Electron Microscopy Center for Materials Research at Argonne National Laboratory, a U.S. Department of Energy Office of Science Laboratory operated under Contract No. DEAC02-06CH11357 by UChicago Argonne, LLC. We thank Tobin Marks for use of the solar cell analyzer and Karen Mulfort for BET analysis.

\section{References}

1. Gratzel, M., Inorg. Chem. 44, 6841 (2005).

2. Gratzel, M., MRS Bull. 30, 23 (2005).

3. Nazeeruddin, M. K.; DeAngelis, F.; Fantacci, S.; Selloni, A.; Viscardi, G.; Liska, P.; Ito, S.; Takeru, B.; Gratzel, M., J. Am. Chem. Soc. 127, 16835 (2005).

4. Kakiuchi, K.; Hosono, E.; Fujihara, S., J. Photoch. Photobio. A 179, 81 (2006).

5. Hosono, E.; Fujihara, S.; Honma, I.; Zhou, H., Advanced Materials 17, 2091 (2005).

6. Keis, K.; Magnusson, E.; Lindstrom, H.; Lindquist, S. E.; Hagfeldt, A., Solar Energy Materials and Solar Cells 73, 51 (2002).

7. Quintana, M.; Edvinsson, T.; Hagfeldt, A.; Boschloo, G., J. Phys. Chem. C 111, 1035 (2007).

8. Law, M.; Greene, L. E.; Johnson, J. C.; Saykally, R.; Yang, P. D., Nat. Mater. 4, 455 (2005).

9. Yoshida, T.; Pauporté, T.; Lincot, D.; Oekermann, T.; Minoura, H., J. Electrochem. Soc. 150, C608 (2003).

10. Paulose, M.; Shankar, K.; Varghese, O. K.; Mor, G. K.; Grimes, C. A., J. Phys. D Appl. Phys. 39, 2498 (2006).

11. Martinson, A. B. F.; McGarrah, J. E.; Parpia, M. O. K.; Hupp, J. T., Phys. Chem. Chem. Phys. 8, 4655 (2006).

12. Galoppini, E.; Rochford, J.; Chen, H.; Saraf, G.; Lu, Y.; Hagfeldt, A.; Boschloo, G., J. Phys. Chem. B 110, 16159 (2006).

13. Greene, L. E.; Yuhas, B. D.; Law, M.; Zitoun, D.; Yang, P., Inorg. Chem. 45, 7535 (2006).

14. Martinson, A. B. F.; Elam, J. W.; Hupp, J. T.; Pellin, M. J., submitted "ZnO Nanotube Based Dye-Sensitized Solar Cells" (2007).

15. Lee, W.; Ji, R.; Gösele, U.; Nielsch, K., Nat. Mater. 5, 741 (2006).

16. Li, A. P.; Müller, F.; Birner, A.; Nielsch, K.; Gösele, U., J. Appl. Phys. 84, 6023 (1998).

17. Masuda, H.; Yada, K.; Osaka, A., Jpn. J. Appl. Phys. 37, L1340 (1998). 